\title{
Cognitive behaviour therapy improved functional impairment and fatigue in patients with chronic fatigue syndrome
}

Deale A, Chalder T, Marks I, et al. Cognitive behavior therapy for chronic fatigue syndrome: a randomized controlled trial. Am J Psychiatry. 1997 Mar;154;408-14.

\section{Objective}

To compare cognitive behaviour therapy (CBT) with relaxation techniques for patients with chronic fatigue syndrome (CFS).

\section{Design}

Randomised controlled trial with 6 month follow up.

\section{Setting}

A hospital clinic in London, England.

\section{Patients}

60 patients (mean age 35 y, 68\% women) with CFS. Patients taking antidepressants or anxiolytics were included if the dose was stable for 3 months before and during the trial; 53 patients $(88 \%)$ completed the study. Exclusion criteria were somatisation disorder, severe depression, ongoing physical investigations, concurrent new treatment, or inability to attend all sessions.

\section{Intervention}

Patients were allocated to CBT $(n=30)$ or relaxation $(n=30)$ for 13 sessions during a 4 to 6 month period. CBT involved therapy engagement; rationale giving; problem assessment and information gathering; and diary keeping of activity, rest, and fatigue (sessions 1 to 3). At session 4, a schedule of graded activity and planned rest was designed. Activity was gradually increased, rest was reduced, and a sleep routine was developed. Cognitive strategies were introduced at session 8. Patients recorded unhelpful or distressing thoughts and practised generating alternatives. Strategies for dealing with setbacks were rehearsed in the final sessions, and maintenance was reinforced. The first 3 sessions of relaxation were similar to those of CBT. In the next 10 sessions progressive muscle relaxation, visualisation, and rapid relaxation were learned and practised twice daily.

\author{
Main outcome measures \\ Functional impairment, fatigue, mood, and global improvement.
}

\section{Main results}

At 6 months, more patients who received CBT than patients who received relaxation improved $(\mathrm{p}<0.001)$, had less fatigue $(\mathrm{p}<0.001)$, and no longer met CFS criteria $(\mathrm{p}<0.001)($ table). Self rated global improvement was better for the CBT group than for the relaxation subgroup $(p<0.01)$. Measures of mood did not differ between groups.

\section{Conclusion}

Cognitive behaviour therapy improved functional impairment and fatigue in patients with chronic fatigue syndrome.

\begin{tabular}{|c|c|c|c|c|c|}
\hline Outcomes at 6 months & $\begin{array}{l}C B T \\
E E R\end{array}$ & $\begin{array}{l}\text { Relaxation } \\
\text { CER }\end{array}$ & $\begin{array}{l}\text { RBI } \\
(95 \% C I)\end{array}$ & $\begin{array}{l}A B I \\
|E E R-C E R|\end{array}$ & $\begin{array}{l}N N T \\
(C I)\end{array}$ \\
\hline $\begin{array}{l}\text { Functional } \\
\text { improvement }\end{array}$ & $70 \%$ & $19 \%$ & $\begin{array}{l}266 \% \\
(74 \text { to } 751)\end{array}$ & $51 \%$ & $\begin{array}{l}2 \\
(1 \text { to } 4)\end{array}$ \\
\hline Less fatigue & $63 \%$ & $15 \%$ & $\begin{array}{l}309 \% \\
(74 \text { to } 960)\end{array}$ & $48 \%$ & $\begin{array}{l}3 \\
(1 \text { to } 5)\end{array}$ \\
\hline $\begin{array}{l}\text { Fails the chronic } \\
\text { fatigue syndrome }\end{array}$ & $56 \%$ & $8 \%$ & $\begin{array}{l}622 \% \\
(116 \text { to } 2585)\end{array}$ & $48 \%$ & $\begin{array}{l}3 \\
(1 \text { to } 4)\end{array}$ \\
\hline
\end{tabular}

*Abbreviations defined in glossary; RBI, ABI, NNT, and CI calculated from data in article.

Source of funding: South East Thames Regional Health Authority Locally Organised Research Scheme (LORS).

For article reprint: Ms A Deale, Department of Psychological Medicine, Kings College Hospital, Denmark Hill, London SE5 9RS, UK. Fax + 44 (0)171 7019044.

Abstract and commentary also published in Evidence-Based Medicine 1977 Jul-Aug;2:106.

\section{Commentary}

CFS is still controversial because little agreement exists about its causes. However, as Deale et al point out, this should not prevent the development of effective treatment. Paradoxically, although CFS may present with physical symptoms, it seems to be becoming clear that a psychological intervention (ie, CBT) is an effective treatment. This is the second major treatment trial of this intervention from England. ${ }^{1}$ Both studies showed that CBT results in significant improvement in about two thirds of patients after 6 months.

The previous study used normal medi- cal treatment as a comparison, whereas the study by Deale et al used relaxation therapy to control for therapist variables, such as the therapist's time and attention given to patients. Apparently, there is something specific about CBT that patients with CFS find helpful.

Hospital outpatient clinics where persons with CFS are treated should have $\mathrm{CBT}$ as part of the treatment regimen that they offer to patients. It is still not clear whether this treatment is useful in primary care settings or whether both cognitive and behavioural components are necessary. The role of antidepressants is also unclear. Additionally, the treatment is time consuming, and about one third of patients do not improve. This group may benefit from more intensive psychotherapy. CBT may also be helpful in parents who present with other "physical symptoms without disease," such as fibromyalgia.

Simon Hatcher, MD

North Shore Hospital Auckland, New Zealand

1 Sharpe M, Hawton K, Simkin S, et al. Cognitive behaviour therapy for the chronic fatigue syndrome: a randomised controlled trial. $B M J$ 1996:312:22-6. 